\title{
Major depressive disorder and sleep disturbance in patients with chronic pain
}

\author{
Patricia C Emery $\mathrm{PhD}^{1}$, Keith G Wilson $\mathrm{PhD}^{1,2,3,4}$, John Kowal PhD1,3,4
}

\begin{abstract}
PC Emery, KG Wilson, J Kowal. Major depressive disorder and sleep disturbance in patients with chronic pain. Pain Res Manag 2014;19(1):35-41.
\end{abstract}

BACKGROUND: Disturbed sleep is a common problem in both chronic pain and major depressive disorder (MDD). Moreover, many patients with chronic pain are depressed.

OBJECTIVES: To examine the effects of depression on the sleep behaviour of chronic pain patients by comparing patients who did or did not meet diagnostic criteria for MDD.

METHODS: A total of 60 patients with chronic musculoskeletal pain underwent structured diagnostic interviews for MDD and insomnia, and completed questionnaires assessing pain severity, disability, sleep quality, beliefs and attitudes about sleep, and sleep hygiene. For four consecutive days, they also completed a sleep diary, and reported on sleep hygiene practices and presleep arousal.

RESULTS: Thirty-three patients (55\%) met diagnostic criteria for MDD, most of whom $(n=32[97 \%])$ also fulfilled criteria for insomnia disorder. Insomnia was also common among patients without MDD (21 of 27 [78\%]). Participants with MDD had higher self-reports of pain, disability, dysfunctional beliefs about sleep, and, on a prospective basis, greater presleep arousal and poorer sleep hygiene. However, diary assessments of specific sleep parameters (eg, sleep onset latency, total sleep time, sleep efficiency) did not differ between the groups.

DISCUSSION: Chronic pain patients with comorbid MDD exhibited more dysfunctional beliefs about sleep, poorer sleep hygiene practices and greater presleep arousal; however, diary-recorded sleep characteristics may not differ from those of patients without MDD. Chronic pain itself may disturb sleep so extensively that MDD introduces little additive effect.

CONCLUSION: MDD in chronic pain may be related to the cognitive and behavioural aspects of insomnia, rather than to an incremental disturbance in the initiation or maintenance of sleep.

Key Words: Chronic pain; Cognitive-behaviour therapy; Depression; Insomnia; Sleep

$\mathrm{E}^{\mathrm{s}}$ idemiological evidence indicates that individuals with chronic pain have high rates of insomnia. Although insomnia as a distinct clinical disorder is experienced by $6 \%$ to $14 \%$ of community residents (1-3), the risk of disturbed sleep is two to five times higher among individuals with chronic pain (4-7). In clinical samples, the association is even more marked, with many studies finding that $50 \%$ to $80 \%$ of chronic pain patients complain of poor sleep (8-21), and some studies reporting rates in excess of $85 \%(22,23)$.

Major depressive disorder (MDD) is also common among patients with chronic pain, with various studies (24-27) finding that approximately $25 \%$ to $40 \%$ of patients fulfill the diagnostic criteria outlined by the Diagnostic and Statistical Manual of Mental Disorders (DSM-IV) (28). Disturbed sleep is actually one of the defining symptoms of MDD in the DSM-IV criteria and, in large studies involving depressed outpatients, $>70 \%$ have reported insomnia $(29,30)$. Collectively, these prevalence estimates suggest that there are many individuals

\section{Le trouble dépressif majeur et les troubles du sommeil chez les patients ayant des douleurs chroniques}

HISTORIQUE : Les troubles du sommeil sont courants en cas de douleu chronique et de trouble dépressif majeur (TDM). De plus, de nombreux patients ayant des douleurs chroniques sont déprimés.

OBJECTIFS : Examiner les effets de la dépression sur le comportement de sommeil des patients ayant des douleurs chroniques en comparant les patients qui respectaient ou non les critères diagnostiques du TDM.

MÉTHODOLOGIE : Au total, 60 patients ayant des douleurs musculosquelettiques chroniques se sont soumis à des entrevues diagnostiques structurées sur la TDM et l'insomnie et ont rempli des questionnaires pour évaluer la gravité de la douleur, l'incapacité, la qualité du sommeil, les croyances et les attitudes au sujet du sommeil, de même que l'hygiène du sommeil. Pendant quatre jours consécutifs, ils ont également rempli un journal du sommeil et rendu compte de leurs pratiques en matière d'hygiène du sommeil et d'éveil avant le sommeil.

RÉSULTATS : Trente-trois patients $(55 \%)$ respectaient les critères diagnostiques de TDM, et la plupart $(\mathrm{n}=32$ [97 \%]) respectaient également les critères de troubles d'insomnie. L'insomnie était également courante chez les patients sans TDM (21 sur 27 [78 \%]). Les participants ayant un TDM déclaraient davantage souffrir de douleurs et d'incapacités, avaient davantage de convictions dysfonctionnelles au sujet du sommeil et, sur une base prospective, un plus grand éveil avant le sommeil et une moins bonne hygiène du sommeil. Cependant, les évaluations de certains paramètres sur le sommeil inscrites dans un journal (p. ex., délai d'endormissement, durée totale de sommeil, efficacité du sommeil) ne différaient pas entre les groupes.

EXPOSÉ : Les patients ayant des douleurs chroniques présentant un TDM comorbide ont davantage de convictions dysfonctionnelles au sujet du sommeil, de moins bonnes pratiques en matière d'hygiène du sommeil et un plus grand éveil avant le sommeil, mais les caractéristiques au sujet du sommeil inscrites dans un journal ne diffèrent pas nécessairement de celles des patients sans TDM. La douleur chronique elle-même peut perturber le sommeil au point que la TDM a peu d'effets supplémentaires.

CONCLUSION : En cas de douleur chronique, la TDM peut être liée aux aspects cognitifs et comportementaux de l'insomnie plutôt qu'à une perturbation incrémentielle de l'endormissement ou du maintien du sommeil.

with chronic pain who are also depressed and experiencing clinically important problems with the initiation or maintenance of sleep. It is not surprising, therefore, that many patients identify improved sleep as an important outcome for pain treatment (31).

One promising intervention in this regard is cognitive-behavioural therapy for insomnia (CBT-I). CBT-I is based on the premise that chronic insomnia arises initially from a transient period of acute sleep disturbance. This becomes maintained persistently through a combination of cognitive processes (eg, dysfunctional attitudes and beliefs about sleep; exaggerated worries about the negative consequences of sleep loss; racing thoughts leading to heightened arousal) and maladaptive coping behaviours (eg, excessive time in bed; napping; overuse of caffeinated products) that interfere with good sleep. Over time, these become ingrained habits, and the bed and bedroom acquire the properties of conditional stimuli for sustained wakefulness $(32,33)$. CBT-I consists of various component interventions designed to counteract this cycle $(33,34)$.

\footnotetext{
${ }^{1}$ School of Psychology; ${ }^{2}$ Department of Medicine, University of Ottawa; ${ }^{3}$ Department of Psychology, The Ottawa Hospital Rehabilitation Centre; ${ }^{4}$ Clinical Epidemiology Program, Ottawa Hospital Research Institute, Ottawa, Ontario

Correspondence: Dr Keith G Wilson, Department of Psychology, The Ottawa Hospital Rehabilitation Centre, 505 Smyth Road, Ottawa, Ontario K1H 8M2. Telephone 613-737-8899 ext 75608, fax 613-737-7056, e-mail kewilson@toh.on.ca
} 
To date, the applicability of CBT-I to insomnia comorbid with chronic pain comes from two lines of research. The first comprises several randomized controlled trials, all of which have found that CBT-I leads to improvements in sleep quality and continuity among patients with chronic pain (35-41). The second consists of studies that identify correlates and predictors of disturbed sleep, using sleepspecific constructs derived from the CBT-I model. These studies have found that patients with worse sleep problems report higher pain intensity $(8,10,11,13-19,22,23,42-44)$ and disability $(9,13,17,22,23)$, as well as greater presleep arousal $(11,23,43)$ and more dysfunctional beliefs about sleep (9).

All of these studies have also found that measures of depression are correlated with the severity of the sleep disturbance, but few have examined the particular question of comorbidity with diagnosed MDD. Wilson et al (21) compared chronic pain patients with insomnia and MDD, insomnia without MDD, and those with neither insomnia nor MDD. They found that patients with both MDD and insomnia reported the most difficulties on measures of affective distress, disability and pain severity, but insomniac patients without MDD had elevated scores on some measures. Importantly, however, the authors did not examine sleep per se in their study, nor did they investigate sleeprelated thoughts and behaviours that are the targets of intervention in CBT-I. In the present study, therefore, we examined the putative impact of depression on the sleep disturbance of patients with chronic pain by comparing those who either did or did not meet diagnostic criteria for MDD on measures relevant to the cognitive-behavioural model of insomnia. Patients completed questionnaires assessing pain severity, disability, sleep quality, and beliefs and attitudes about sleep. Moreover, they also completed prospective sleep diaries and reported, on a daily basis, information regarding their sleep hygiene practices and levels of presleep arousal.

\section{Participants}

Participants were patients referred to an interdisciplinary chronic pain rehabilitation program at the Ottawa Hospital Rehabilitation Centre (Ottawa, Ontario) $(45,46)$. They were approached either at an initial orientation session to the program $(n=278)$ or by mail $(n=57)$. Of these, $270(80.6 \%)$ declined to participate or did not respond to the invitation for participation. A total of 65 volunteers were screened initially, with five withdrawing before completion of the prospective diaries. Thus, the 60 individuals who completed the study represent $17.9 \%$ of the patients who were approached during a 24 -month recruitment period.

The research was approved by an institutional research ethics review board, and all participants completed an acknowledgement of informed consent. However, approval did not extend to reviewing records of patients who did not participate; therefore, whether they may have differed from patients who volunteered is unknown.

The final sample comprised 44 women $(73.3 \%)$ and 16 men $(26.7 \%)$, with a mean $( \pm$ SD) age of $46.0 \pm 9.2$ years (range 21 to 60 years). Their mean duration of chronic pain was $7.1 \pm 5.6$ years (range nine months to 24.5 years). The locations of the primary pain complaint were diverse and included the back (35.0\%), followed by widespread body pain (23.3\%), neck (16.7\%), shoulders $(8.3 \%)$, legs/feet $(6.7 \%)$ or other sites (eg, hands or torso, $10.0 \%)$.

\section{Procedures}

Each participant was interviewed individually and then provided with a set of questionnaires, which were completed before the prospective component of the study. These questionnaires addressed global aspects of pain, disability, mood and sleep. Participants were also provided with daily diaries, which they were asked to complete over four consecutive days. The four days of recording were undertaken because sleep tends to vary across nights, and greater reliability is achieved through longer periods of recording (47). However, no specific hypotheses were generated regarding differences between groups over time; therefore, the analyses focused on data averaged over the four days.

\section{MEASURES}

Interview assessment

Primary Care Evaluation of Mental Disorders: The Primary Care Evaluation of Mental Disorders (PRIME-MD) (48) diagnostic protocol consists of two components. First, a self-report screening questionnaire initially assesses the core criterion symptoms of a range of DSM-IV disorders. This is followed by a structured interview that provides complete coverage of all criterion symptoms for disorders suggested by items endorsed on the screen. Spitzer et al (48) reported good concordance between PRIME-MD diagnoses and those of independent mental health professionals ( $\kappa=0.61$ for MDD). For the present purpose, modules relevant to the diagnoses of depressive and anxiety disorders were administered; however, an interview guide that was enhanced using an approach reported by Wilson et al (49) was used. This approach calls for more detailed probing into specific symptoms of anxiety, depressed mood, and loss of interest or pleasure than is included in the original PRIME-MD, with the aim of ensuring strict adherence to DSM-IV severity thresholds. This modification has been used in previous studies of medical patients $(49,50)$.

Structured Interview for Sleep Disorders: The Structured Interview for Sleep Disorders (SIS-D) (51) is a structured interview that assesses specific sleep complaints according the DSM-III-R classification system. The interview was revised slightly to conform to DSM-IV revisions (35). The diagnosis of insomnia required a complaint of difficulty initiating or maintaining sleep of at least one month's duration, along with an acknowledgement of significant distress or functional impairment (28). Schramm et al (51) reported high levels of inter-rater agreement for SIS-D diagnoses $(\kappa=0.86$ for insomnia related to an organic factor) and good concordance with clinical judgements based on polysomnography.

The SIS-D was supplemented with an interviewer rating of global insomnia severity, which was taken from the Schedule for Affective Disorders and Schizophrenia (52). This measure could range from 1 (no insomnia) to 6 (extreme; eg, claims he/she almost never sleeps and feels exhausted the next day). This insomnia rating was used by Wilson et al (21) in their study of MDD and sleep in patients with chronic pain.

Baseline questionnaires: Pain, disability, medication use and mood Pain severity: Participants rated the overall severity of their worst, least and average pain levels over the past two weeks, as well as their current pain. Each item was rated on an 11 -point scale $(0=$ no pain and 10 = "as intense as you can imagine") (53). The scores were summed and divided by four to create an average score for each participant. The use of average scores, rather than totals, permits a more direct comparison of the baseline and prospective pain assessments.

Functional disability: Disability was assessed with a questionnaire asking respondents to rate the degree of difficulty $(0=$ no difficulty to 4 = unable to do) they experienced in completing 16 common tasks (eg, making meals, dressing, climbing steps) (54). Scores on this scale have been found to be sensitive to treatment effects in pain management (45), and its internal consistency in the present sample was excellent $(\alpha=0.88)$.

Medication Quantification Scale: Patients with chronic pain often use medications that can affect sleep. The Medication Quantification Scale version III requires respondents to report their typical daily consumption of prescription and over-the-counter drugs (type, dose and number of pills) $(55,56)$. Scores are calculated based on weights assigned to different classes of medications, depending on their potential for adverse effects. The Medication Quantification Scale has shown excellent inter-rater reliability in chronic pain settings, and has been found to vary appropriately with changes in medication use (55). 
Beck Depression Inventory-II: The Beck Depression Inventory-II (BDI-II) (57) is a self-report measure of depressive symptomatology experienced over the past two weeks. Respondents rate the severity of each of 21 symptoms on a 0 to 3 scale. Summary scores can range from 0 to 63 , with higher totals indicating higher levels of depression. The BDI-II is a widely used measure with established validity (57), including among the medically ill (58).

\section{Baseline questionnaires: Sleep quality, knowledge, behaviours and beliefs}

Pittsburgh Sleep Quality Index: This 19-item self-report measure of sleep characteristics has high sensitivity and specificity for distinguishing good and poor sleepers in clinical settings (59). It reviews typical sleep habits and difficulties over the past month, and provides a global score of subjective sleep impairment ranging from 0 to 21, with higher scores indicating greater difficulty. The Pittsburgh Sleep Quality Index (PSQI) has good internal consistency and test-retest reliability (59), and has been used previously in studies of chronic pain $(9,19,20,22,23,42,60)$. Sleep Hygiene Awareness and Practice Scale: The Sleep Hygiene Awareness and Practice Scale (SHAPS) was developed to assess the degree of awareness of sleep hygiene principles and the extent to which they are practiced (61). The Awareness section of the SHAPS comprises two parts. The first is a Sleep Hygiene Knowledge Scale that includes 13 items assessing general awareness of the impact of various activities on sleep (eg, napping, exercising strenuously before bed). Each item is rated on a 7 -point scale $(1=$ very beneficial to sleep to 7 = very disruptive to sleep). A scoring protocol recommended by Lacks and Rotert (61) was used, in which correct answers were given one point, incorrect answers three points and omitted responses two points. Thus, this section ranges from 13 to 39, with higher scores indicating a lack of awareness of good sleep hygiene principles.

The second awareness component of the SHAPS is a Caffeine Knowledge Scale, in which participants report whether each of 18 common foods, beverages or nonprescription medications contain caffeine. The Caffeine Knowledge score was derived by taking the number of items answered correctly and dividing by the number of items attempted. Respondents were instructed to omit any products with which they were unfamiliar. This results in a score ranging from $0 \%$ to $100 \%$ correct.

The Sleep Hygiene Practice section contains 19 items that present examples of specific practices that can promote or interfere with good sleep. The respondents indicate the number of nights per week they engage in these activities (ie, from zero to seven days per week). Thus, total scores can range from 0 to 133 , with higher scores indicating poor sleep hygiene practices.

Although the SHAPS has not been used extensively, it is one of the few measures that attempts to assess this important aspect of the cognitive-behavioural model of insomnia. In the original validation study, it was found that insomniacs actually had better general knowledge about sleep hygiene than good sleepers, but practiced it less (61). Dysfunctional Beliefs and Attitudes about Sleep scale: The most widely used measure for assessing maladaptive beliefs in insomnia is the Dysfunctional Beliefs and Attitudes about Sleep scale (DBAS) (33), which is composed of various statements reflecting attitudes and beliefs about sleep commonly held by individuals with insomnia (eg, misconceptions about the causes of insomnia; amplification of the consequences of sleep loss). According to Morin (33), faulty beliefs about sleep and the effects of sleep loss can lead to worry and increased arousal at night and, as a result, to a more severe experience of insomnia. Although various versions and scoring methods have been suggested for the DBAS, the original 30-item questionnaire was used in the present study and respondents were asked to rate each item on a 10-point Likert scale $(1=$ strongly agree to $10=$ strongly disagree $)$ (62). The total score reflects increasingly dysfunctional beliefs about sleep. Different versions of the DBAS have been found to have good psychometric characteristics $(62,63)$, and it has been used in recent studies of sleep and chronic pain $(9,43)$.
Prospective questionnaires: Pain, affect, presleep arousal and sleep hygiene daily practice

Pain severity: In the daily diaries, current pain was measured four times during the day (first thing in the morning, midday, suppertime and bedtime) using the same 11-point scale as for the retrospective baseline assessment (53). Over four days of monitoring, this resulted in 16 data points per participant, from which an average pain score was computed. Jensen and McFarland (64) have shown that multiple ratings of pain over successive days provide estimates of average pain that have good psychometric characteristics. In the present study, the alpha was 0.97 , indicating excellent internal consistency.

Positive and Negative Affect Schedule: The Positive and Negative Affect Schedule (PANAS) (65) comprises 10 positive and 10 negative adjectives describing emotional states. Using a 5 -point scale $(1=$ very slightly to $5=$ very much), the respondent rates the extent to which each adjective is consistent with his or her current emotional state. The resulting positive and negative affect subscales are conceptualized as orthogonal to one another; that is, positive and negative affect are considered to be independent dimensions rather than opposite poles of the same dimension $(65,66)$. Indeed, the two subscales tend not to be correlated significantly with one another, and each has good internal consistency and test-retest reliability across various populations and time frames $(65,66)$.

In the present study, participants completed the PANAS each morning and evening. The average scores across eight administrations were examined.

Presleep Arousal Scale: The Presleep Arousal Scale (PSAS) is composed of two eight-item subscales measuring cognitive and somatic arousal within the presleep context (67). Respondents use Likert scales to rate $(1=$ not at all to $5=$ extremely $)$ the degree to which they experienced anxious cognitive and somatic arousal while trying to fall asleep the night before. Symptoms such as increased heart rate and muscle tightness are examples of somatic arousal; symptoms of cognitive arousal include racing thoughts, worrying and rumination. Both subscales have been shown to possess adequate internal and test-retest reliability (67). In previous research, PSAS scores have been found to differentiate good and poor sleepers (67), including those with chronic pain $(11,23)$. For the present purpose, average scores for each subscale were examined, collapsed across the four mornings of reporting.

Sleep Hygiene Daily Practice: This 19-item scale was adapted for use in the present study. It was completed by participants on arising in the morning. Its content was identical to the Practice section of the SHAPS, but applied to prospective rather than retrospective reporting. Specifically, participants were asked to indicate whether they had engaged in any of the problematic sleep-related behaviours the previous day. The number of reported behaviours was obtained (range $=0$ to 19 each day), and the total over four days was examined.

\section{Daily sleep diary}

The sleep diary was based on a format described by Haythornthwaite et al (47). It assessed total sleep time (number of hours slept), sleep onset latency (SOL; estimated number of minutes to fall asleep initially), frequency and duration of nocturnal awakenings (for calculating wake time after sleep onset [WASO]) and overall time in bed, which collectively allowed for the determination of sleep efficiency (SEF; percentage of time in bed actually sleeping). Participants were instructed to complete the diary on arising in the morning, with regard to the preceding night's sleep. Although sleep data among poor sleepers are inherently variable, these measures have been shown to possess adequate test-retest stability among patients with chronic pain when recorded over a period of at least four days (47).

In addition, the diary included a daily rating of the overall quality of the previous night's sleep. These ratings were made on a 0 to 10 point scale, which were summed over the four days and reduced to a single average score for each participant. 


\section{TABLE 1}

Demographic characteristics and interview results of participants with or without major depressive disorder (MDD)

\begin{tabular}{|c|c|c|c|c|}
\hline \multirow[b]{2}{*}{ Variable } & \multicolumn{2}{|c|}{ Group } & \multicolumn{2}{|c|}{ Statistics } \\
\hline & $\begin{array}{c}\text { MDD } \\
(n=33)\end{array}$ & $\begin{array}{c}\text { Non-MDD } \\
(n=27)\end{array}$ & $\begin{array}{l}t \text { or } x^{2} \\
\text { value }\end{array}$ & $\mathbf{P}$ \\
\hline \multicolumn{5}{|l|}{ Demographics } \\
\hline Sex, men/women, $\mathrm{n} / \mathrm{n}$ & $6 / 27$ & $10 / 17$ & 2.70 & 0.10 \\
\hline Age, years, mean $\pm S D$ & $45.24 \pm 8.76$ & $46.93 \pm 9.79$ & $<1$ & $>0.10$ \\
\hline Pain duration, years, mean \pm SD & $6.97 \pm 4.63$ & $7.19 \pm 6.71$ & $<1$ & $>0.10$ \\
\hline \multicolumn{5}{|l|}{ PRIME-MD Disorder } \\
\hline MDD in partial remission & - & $7(25.9)$ & & \\
\hline Panic disorder & $10(30.3)$ & $3(11.1)$ & 3.22 & 0.07 \\
\hline Generalized anxiety disorder & $19(57.6)$ & $4(14.8)$ & 11.49 & 0.001 \\
\hline SIS-D Insomnia & $32(97.0)$ & $21(77.8)$ & 5.31 & 0.021 \\
\hline $\begin{array}{l}\text { Interviewer insomnia rating, } \\
\text { mean } \pm \text { SD }\end{array}$ & $5.06 \pm 1.00$ & $4.48 \pm 1.05$ & 2.18 & 0.030 \\
\hline
\end{tabular}

Data presented as $n(\%)$ unless otherwise indicated. PRIME-MD Primary Care Evaluation of Mental Disorders; SIS-D Structured Interview for Sleep Disorders

Data analyses

Participants who did or did not meet criteria for current MDD based on PRIME-MD interviews were identified. These groups were then compared initially with respect to demographic characteristics, concurrent other PRIME-MD disorders, the SIS-D diagnosis of insomnia and the interviewer global rating of insomnia severity. These comparisons comprised $t$ tests or $\chi^{2}$ analyses, as appropriate.

The ensuing analyses consisted of a series of $t$ tests comparing participants with or without current MDD on various baseline and prospective measures. Given the number of comparisons, adjustments were made to protect against type I error. Specifically, various dependent variables were first categorized into conceptual families (68), and then $\alpha$-level corrections were applied to multiple comparisons within each family, using Benjamini and Hochberg's method (69) for controlling the false discovery rate. Thus, the $\alpha$-level for each comparison was adjusted individually depending on the number of comparisons within a family. The families consisted of: baseline questionnaires of pain severity, disability, medication use and mood; baseline questionnaires of sleep quality, sleep hygiene knowledge and practice, and beliefs about sleep; prospective measures of pain severity, affect, presleep arousal and daily sleep hygiene practice; and sleep diary measures of total sleep time, SOL, WASO, SEF and sleep quality.

\section{RESULTS}

Demographic characteristics and interview findings

Based on PRIME-MD diagnostic interviews, 33 individuals met DSM-IV criteria for MDD and 27 did not, representing an overall prevalence of $55 \%$. As shown in Table 1, participants with and without MDD did not differ significantly with regard to age, sex or time elapsed since the development of the chronic pain condition.

Other co-occurring mental disorders were also common among the participants. For example, among those without current MDD, > $25 \%$ met diagnostic criteria for MDD in partial remission, indicating that they could not be considered entirely free of problems with depression. The prevalence of panic disorder was somewhat higher among participants with $\operatorname{MDD}\left(30.3 \%\right.$ versus $\left.11.1 \% ; \chi^{2}[1]=3.22 ; \mathrm{P}=0.07\right)$, while concurrent generalized anxiety disorder was significantly higher ( $57.6 \%$ versus $\left.14.8 \% ; \chi^{2}[1]=11.49 ; \mathrm{P}=0.001\right)$.

Insomnia was very common among both groups of participants, with 53 of $60(88.4 \%)$ fulfilling DSM-IV criteria. However, the prevalence was higher among those with MDD, for whom it was nearly universal (97.0\%), than among those without current $\operatorname{MDD}(77.8 \%)\left(\chi^{2}[1]=5.31\right.$; $\mathrm{P}=0.021)$. In addition, the interviewer global rating of insomnia severity was higher for the MDD group $(t[58]=2.18 ; \mathrm{P}=0.03)$.
TABLE 2

Baseline questionnaire scores of participants with or without major depressive disorder (MDD)

\begin{tabular}{|c|c|c|c|c|}
\hline \multirow[b]{2}{*}{ Variable } & \multicolumn{2}{|c|}{ Group } & \multicolumn{2}{|c|}{ Statistics } \\
\hline & MDD (n=33) & Non-MDD $(n=27)$ & $t$ & $\mathbf{P}$ \\
\hline \multicolumn{5}{|l|}{ Pain and mood } \\
\hline Pain severity & $7.12 \pm 1.73$ & $5.93 \pm 1.52$ & 2.81 & 0.007 \\
\hline Disability & $31.15 \pm 9.01$ & $26.00 \pm 8.52$ & 2.26 & 0.028 \\
\hline BDI-II & $34.58 \pm 8.55$ & $20.41 \pm 7.85$ & 6.62 & $<0.001$ \\
\hline MQS & $24.14 \pm 10.95$ & $24.55 \pm 15.93$ & $<1$ & $>0.10$ \\
\hline \multicolumn{5}{|l|}{ Sleep } \\
\hline PSQI & $15.48 \pm 3.68$ & $14.84 \pm 4.06$ & 1.00 & $>0.10$ \\
\hline \multicolumn{5}{|l|}{ SHAPS } \\
\hline SH knowledge & $21.24 \pm 4.78$ & $20.78 \pm 5.20$ & $<1$ & $>0.10$ \\
\hline Caffeine knowledge & $67.86 \pm 12.74$ & $76.45 \pm 10.19$ & 2.79 & 0.007 \\
\hline SH usual practice & $35.61 \pm 15.30$ & $28.31 \pm 13.80$ & 1.90 & 0.06 \\
\hline DBAS & $159.82 \pm 40.25$ & $137.52 \pm 33.23$ & 2.31 & 0.025 \\
\hline
\end{tabular}

Data presented as mean $\pm S D$ unless otherwise indicated. BDI-Il Beck Depression Inventory - II; DBAS Dysfunctional Attitudes and Beliefs about Sleep scale; MQS Medication Quantification Scale; PSQI Pittsburgh Sleep Quality Index; SH Sleep hygiene; SHAPS Sleep Hygiene Awareness and Practice Scale

Baseline questionnaires: Mood and pain

Not surprisingly, the MDD and non-MDD groups differed significantly on the BDI-II measure of depressive symptomatology $(t[58]=6.62$; $\mathrm{P}<0.001)$. As shown in Table 2, the participants with MDD also reported more severe pain $(t[58]=2.81 ; \mathrm{P}=0.007)$ and greater disability $(t[58]=2.26 ; \mathrm{P}=0.028)$. However, the groups did not differ with respect to medication use $(\mathrm{t}[58]<1)$.

Baseline questionnaires: Sleep

The MDD and non-MDD groups had comparable scores on the PSQI measure of sleep disturbance $(t[58]=1.00 ; \mathrm{P}>0.10)$ but there were several noteworthy differences in sleep attitudes and behaviours. Specifically, participants in the MDD group were significantly less knowledgeable about caffeinated products $(t[56]=2.79, \mathrm{P}=0.007)$. Their scores on the DBAS also suggested a tendency toward more dysfunctional attitudes and beliefs about sleep $(t[58]=2.31 ; \mathrm{P}=0.025)$, albeit only marginally with a corrected $\mathrm{P}=0.020$. Retrospective scores on the SHAPS subscales of sleep hygiene knowledge and usual practice were not statistically different between the groups, particularly when conservative criteria were applied.

\section{Prospective assessment: Questionnaire measures}

As with the baseline assessment, the participants with MDD reported higher pain severity during the four-day prospective recording period $(t[58]=3.42 ; \mathrm{P}=0.001)$ (Table 3$)$. They also reported more negative affect on the PANAS $(t[56]=4.20 ; \mathrm{P}<0.001)$, although there were no differences between groups on the positive affect scale $(t[56]<1)$.

On the diary measure of sleep hygiene daily practice, participants with MDD reported that they had engaged in more behaviours that are generally incompatible with good sleep $(t[58]=3.05 ; \mathrm{P}=0.003)$. They also recorded higher arousal ratings on the PSAS, especially with respect to the cognitive dimension $(t[58]=2.69 ; \mathrm{P}=0.009)$; their scores on the somatic dimension were also elevated, albeit less reliably $(t[58]=1.81 ; \mathrm{P}=0.07)$.

Daily sleep diary

The average measures of sleep quality and continuity reported on the daily sleep diaries are presented in Table 3. None of these measures showed any significant differences between participants diagnosed with or without MDD (all $\mathrm{P}>0.10$ ).

\section{DISCUSSION}

Although the issues of depression and disturbed sleep in chronic pain have been addressed in previous research, most studies have used 
global measures of insomnia applied retrospectively to patients' recollections of 'typical' sleep. We replicated this approach, but extended it by incorporating structured interviews for the diagnosis of mental disorders and prospective daily diaries for assessing pain, mood and sleep. Moreover, the selection of assessment measures was guided by the cognitive-behavioural model of insomnia, so that the results would inform future research and practice into CBT-I for patients with chronic pain who may also present with MDD.

According to the cognitive-behavioural model, chronic insomnia evolves from an initial episode of poor sleep, such as often arises during times of stress. As Currie et al (35) point out, this initial sleep loss could occur with the onset of a pain condition itself. Over time, the individual may attempt to cope with sleep loss using counterproductive behaviours, such as napping, excessive caffeine use and spending extended periods of time in bed. At the same time, there may be a tendency to catastrophize about insomnia, exaggerate the negative consequences of sleep loss, develop anticipatory apprehension as bedtime approaches and worry in bed. These cognitive responses, in turn, increase the level of arousal around bedtime. Then, through a process of classical conditioning involving long periods of lying awake in bed, the bed and bedroom become conditional cues for a psychophysiological state of alert wakefulness rather than relaxed sleepiness. Over weeks, months and years, this repetitive cycle becomes chronic.

In general, there was good evidence from the present study that some aspects of the cognitive-behavioural model were even more relevant to participants with MDD than those without MDD. First, there were differences in knowledge about sleep hygiene, at least with respect to an understanding of caffeinated products. We did not assess whether this translated into an elevated use of those products. Nevertheless, the finding points to a diminished appreciation by patients with MDD of the potential role of environmental factors in disrupting sleep.

Second, although group differences in retrospective reports of problematic behaviours did not emerge in the baseline SHAPS, the diary assessments of sleep-incompatible behaviours indicated that they were, in fact, used more often by participants with MDD. Hence, the more distinctly behavioural dimension of the cognitive-behavioural model appears to be relevant to patients with chronic pain and comorbid MDD. It would be beneficial in future research to address whether there are specific behaviours, such as daytime napping, that are more likely to be used by these individuals.

Third, there was evidence that patients with MDD tended to have more dysfunctional attitudes and beliefs about sleep. This finding is in keeping with principles of cognitive-behaviour therapy in general, which posit that distorted cognitive processes are a core feature of depression.

Fourth, the daily diaries clearly showed that the participants with MDD had more negative affect through the day, higher pain levels and greater cognitive arousal in bed. Individually, each of these issues has been implicated in the sleep disturbance experienced by individuals with chronic pain $(9,11,16,21,23,42,70)$. Collectively, it could be hypothesized that they combine to produce an especially severe pattern of insomnia.

On the other hand, there were actually few differences between the groups in the measures most relevant to sleep itself. The diary measures of sleep quality, duration and continuity were comparable between the MDD and non-MDD groups, as were baseline scores on the PSQI. The only difference in a sleep-related parameter was the interviewer's rating of global insomnia severity, which relied on patients' retrospective reports of typical sleeping difficulties. Further prospective research incorporating polysomnography or ambulatory monitoring would be required to examine the extent to which objectively measured sleep parameters are disrupted in this group. Harman et al (71) compared polysomnographic sleep in small groups of depressed and nondepressed patients with chronic low back pain. Similar to the present study, they found no differences in sleep onset, duration or fragmentation. Until the issue is clarified further, therefore, it would appear that chronic pain itself may disturb sleep to an extent that comorbid MDD introduces little additive effect. For example, on the daily sleep diary, participants in the non-MDD group reported an SOL of $>40 \mathrm{~min},>2 \mathrm{~h}$ of WASO,
TABLE 3

Prospective assessments of participants with or without major depressive disorder (MDD)

\begin{tabular}{lcccc}
\hline & \multicolumn{2}{c}{ Group } & \multicolumn{2}{c}{ Statistics } \\
\cline { 2 - 5 } Variable & MDD $(\mathbf{n}=\mathbf{3 3})$ & Non-MDD $(\mathbf{n}=\mathbf{2 7})$ & $\boldsymbol{t}$ & $\mathbf{P}$ \\
\hline Questionnaires & & & & \\
Pain severity & $7.28 \pm 1.70$ & $5.83 \pm 1.53$ & 3.42 & 0.001 \\
PANAS & & & & \\
$\quad$ Positive & $18.50 \pm 7.65$ & $18.18 \pm 5.20$ & $<1$ & $>0.10$ \\
$\quad$ Negative & $20.73 \pm 6.82$ & $14.08 \pm 4.80$ & 4.20 & $<0.001$ \\
PSAS & & & & \\
Somatic & $16.38 \pm 5.12$ & $14.12 \pm 4.27$ & 1.81 & 0.070 \\
Cognitive & $21.11 \pm 7.66$ & $16.44 \pm 5.30$ & 2.69 & 0.009 \\
SH daily practice & $18.94 \pm 7.52$ & $13.70 \pm 5.28$ & 3.05 & 0.003 \\
Daily sleep diary & & & & \\
SOL, min & $52.94 \pm 49.98$ & $43.76 \pm 37.02$ & $<1$ & $>0.10$ \\
WASO, min & $131.90 \pm 88.67$ & $125.45 \pm 91.01$ & $<1$ & $>0.10$ \\
TST, $h$ & $5.78 \pm 1.81$ & $6.12 \pm 1.48$ & $<1$ & $>0.10$ \\
SEF, \% & $65.46 \pm 17.97$ & $69.40 \pm 16.39$ & $<1$ & $>0.10$ \\
Sleep quality & $3.93 \pm 1.71$ & $4.30 \pm 1.62$ & $<1$ & $>0.10$ \\
\hline
\end{tabular}

Data presented as mean $\pm S D$ unless otherwise indicated. PANAS Positive and Negative Affect Scale; PSAS Pre-Sleep Arousal Scale; SEF Sleep efficiency; SH Sleep hygiene; SOL Sleep onset latency; TST Total sleep time; WASO Wake after sleep onset;

approximately $6 \mathrm{~h}$ of total sleep, sleep quality ratings of only 4.30 on an 11 -point scale and SEF $<70 \%$. Clinically, this is indicative of very poor sleep, comparable with that of participants with MDD. Thus, MDD may exacerbate the cognitive and behavioural determinants of insomnia and, perhaps, promote the development of chronicity or resistance to improvement. However, this occurs against a background of sleep that is already highly disrupted by the experience of chronic pain.

Based on the cognitive-behavioural model, CBT-I has been examined recently with patients who have insomnia that is comorbid with chronic pain (35-41). These studies have all found that CBT-I leads to improvements in various aspects of sleep, suggesting that it may be generally helpful in pain management practice. There is one caveat, however; there is no evidence that CBT-I is either effective or appropriate for chronic pain patients with concurrent MDD, which raises the issue of applicability to this group. The relevant studies to date have either not considered the mental health status of participants $(37-41)$ or have deliberately excluded those who meet criteria for concurrent MDD $(35,36)$. The reasons for such exclusion centre around two primary concerns (72). The first has to do with the fact that depression is a treatable condition and adequate treatment of the mental health issues may itself resolve the sleep problem. The second has to do with components of the CBT-I intervention, such as sleep restriction and stimulus control, which require that patients get out of bed whenever they experience extended wakefulness. For depressed individuals in pain, who may be prone to ruminative brooding and suicidal ideation, the recommendation to stay up late into the night has the potential for adverse effects and, therefore, requires a strong evidence base. Thus, the present study provides empirical support for the association of cognitive-behavioural factors with the sleep disturbance of chronic pain patients with comorbid MDD, but the extension of CBT-I to this group should nevertheless be approached with caution.

There are limitations to the study that are important to consider. For example, we found that the prevalence of both MDD (55\%) and insomnia (88\%) were higher in this sample than in most other studies reported in the literature. This may have to do with the characteristics of the patients referred to the rehabilitation program, who tend to be quite disabled by their chronic pain (45). Patients were also asked to volunteer for a study that required a sustained commitment over multiple days. We do not have information about patients who chose not 
to participate, but it is possible that individuals with a more severe insomnia problem also had the greatest interest in sleep research. Accordingly, the prevalence rates of the diagnosed disorders may be high relative to some studies, but this would not affect the internal comparisons of participants with or without MDD.

To capture all of the relevant aspects of sleep, pain and mood from the perspective of a cognitive-behavioural model, this exploratory study included a wide range of variables. This necessarily increased the risk of type I error. Although statistical adjustments were made for multiple comparisons, future replication is required to confirm the conclusions. Among the major findings was that the comparisons made on the basis of sleep diaries did not actually differ between the MDD and non-MDD groups; therefore, the problem of false positives introduced by multiple comparisons is not an issue with regard to those particular measures.

It should also be noted that participants in the non-MDD group were not selected to be free of other comorbid mental health problems and their average score on the BDI-II, in fact, fell in the range of moderate depression (58). Indeed, $>25 \%$ of this group met diagnostic criteria for MDD in partial remission. It is now well established that sleep disturbance is a common residual symptom among patients who respond to treatment for $\operatorname{MDD}(73,74)$. In addition, generalized anxiety disorder, which also includes insomnia among its diagnostic criteria, was represented in both groups, but especially in those with MDD. Therefore, the participants with MDD had more pervasive and severe mental health problems; thus, attributing all of the findings to

\section{REFERENCES}

1. Morin CM, LeBlanc M, Bélanger L, Ivers H, Mérette C, Savard J. Prevalence of insomnia and its treatment in Canada. Can J Psychiatry 2011;56:540-8.

2. Ohayon MM, Reynolds III CF. Epidemiological and clinical relevance of insomnia diagnosis algorithms according to DSM-IV and International Classification of Sleep Disorders (ICSD). Sleep Med 2009;10:952-60.

3. Ohayon MM, Sagales T. Prevalence of insomnia and sleep characteristics in the general population of Spain. Sleep Med 2010;11:1010-8.

4. Louie GH, Tektonidou MG, Caban-Martinez AJ, Ward MM. Sleep disturbances in adults with arthritis: Prevalence, mediators, and subgroups at greatest risk. Data from the 2007 National Health Interview Survey. Arthritis Care Res 2011;63:247-60.

5. Ohayon MM. Relationship between chronic painful physical condition and insomnia. J Psychiatric Res 2005;39:151-9.

6. Sivertsen B, Krokstad S, Øverland S, Mykletun A.

The epidemiology of insomnia: Associations with physical and mental health. The Hunt-2 study. J Psychosom Res 2009;67:109-16.

7. Zhang J, Lam SP, Li SX, et al. Long-term outcomes and predictors of chronic insomnia: A prospective study in Hong Kong Chinese adults. Sleep Med 2012;13:455-62.

8. Alsaadi SM, McAuley JH, Hush JM, Maher CG. Erratum to: Prevalence of sleep disturbance in patients with low back pain. Eur Spine J 2012;21:554-60.

9. Ashworth PCH, Davidson KM, Espie CA. Cognitive-behavioral factors associated with sleep quality in chronic pain patients. Behav Sleep Med 2010;8:28-39.

10. Atkinson JH, Ancoli-Israel S, Slater MA, Garfin SR, Gillin JC. Subjective sleep disturbance in chronic back pain. Clin J Pain 1988;4:225-32.

11. Dillon HR, Thomas SJ, Lichstein KL. Cognitive arousal and sleep complaints in chronic pain. Cogn Ther Res 2012;36:149-55.

12. Marty M, Rozenberg S, Duplan B, Thomas P, Duquesnoy B, Allaert F. Quality of sleep in patients with chronic low back pain: A case-control study. Eur Spine J 2008;17:839-44.

13. McCracken LM, Iverson GL. Disrupted sleep patterns and daily functioning in patients with chronic pain. Pain Res Manag 2002;7:75-9.

14. McCracken LM, Williams JL, Tang NK. Psychological flexibility may reduce insomnia in persons with chronic pain: A preliminary retrospective study. Pain Med 2011;12:904-12.

15. Morin CM, Gibson D, Wade J. Self-reported sleep and mood disturbance in chronic pain patients. Clin J Pain 1998;14:311-4.

16. O'Brien EM, Waxenberg LB, Atchison JW, et al. Intraindividual variability in daily sleep and pain ratings among chronic pain
MDD alone may not fully capture the nature of the distress in which their sleep problem is embedded. This may be characteristic, however, of the clinical reality of MDD and insomnia that occur in the context of chronic pain.

\section{CONCLUSIONS}

In this group of individuals with chronic pain, insomnia was a common problem, even among those who did not meet diagnostic criteria for current MDD. Indeed, sleep diary data showed little difference between participants with or without MDD on measures of sleep onset and continuity. However, self-reports based on the cognitivebehavioural model of insomnia were characterized by more dysfunctional attitudes and beliefs about sleep, greater presleep arousal and poorer sleep hygiene. Thus, chronic pain itself may disturb sleep so extensively that MDD introduces little incremental deficit in the initiation or maintenance of sleep. Rather, MDD in chronic pain may be more related to the cognitive and behavioural aspects of insomnia.

DISCLOSURE: The authors have no conflicts of interest regarding this article.

ACKNOWLEDGEMENT: This research was supported by the Centre for Rehabilitation Research and Development of the Ottawa Hospital Research Institute, Ottawa, Ontario.

patients: Bidirectional association and the role of negative mood. Clin J Pain 2011;27:425-33.

17. Pilowsky I, Crettenden I, Townley. Sleep disturbance in pain clinic patients. Pain 1985;23:27-33.

18. Tang NKY, Wright KJ, Salkovskis PM. Prevalence and correlates of clinical insomnia co-occurring with chronic back pain. J Sleep Res 2007; 16:85-95.

19. Valenza MC, Valenza G, González-Jiménez E, et al. Alteration in sleep quality in patients with mechanical insidious neck pain and whiplash-associated neck pain. Am J Phys Med Rehabil 2012;91:584-91.

20. van de Water AT, Eadie J, Hurley DA. Investigation of sleep disturbance in chronic low back pain: An age- and gender-matched case control study over a 7-night period. Manual Ther 2011;550:550-6.

21. Wilson KG, Eriksson MY, D’Eon JL, Mikail SF, Emery PC. Major depression and insomnia in chronic pain. Clin J Pain 2002;18:77-83.

22. Naughton F, Ashworth P, Skevington SM. Does sleep quality predict pain-related disability in chronic pain patients? The mediating role of depression and pain severity. Pain 2007;127:243-52.

23. Smith MT, Perlis ML, Smith MS, Giles DE, Carmody TP. Sleep quality and presleep arousal in chronic pain. J Behav Med 2000;23:1-13.

24. Geisser ME, Roth RS, Theisen ME, Robinson ME, Riley JL. Negative affect, self-report of depressive symptoms, and clinical depression: Relation to the experience of chronic pain. Clin J Pain 2000;16:110-20.

25. Ho, PT, Li CF, Ng, YK, Tsui SL, Ng KF. Prevalence of and factors associated with psychiatric morbidity in chronic pain patients. J Psychosom Res 2011;70:541-7.

26. Knaster P, Karlsson H, Estlander AM, Kalso E. Psychiatric disorders as assessed with SCID in chronic pain patients: The anxiety disorders precede the onset of pain. Gen Hosp Psychiatry 2012;34:46-52.

27. Wilson KG, Mikail SF, D'Eon JL, Minns J. Alternative diagnostic criteria for major depressive disorder in patients with chronic pain. Pain 2001;91:227-34.

28. American Psychiatric Association. Diagnostic and Statistical Manual of Mental Disorders, 4th edn. Washington, DC: American Psychiatric Association, 1994.

29. Sunderajan P, Gaynes BN, Wisniewski SR, et al. Insomnia in patients with depression: A STAR*D report. CNS Spectrums 2010;15:394-404.

30. Zimmerman M, McGlinchey JB, Young D, Chelminski I. Diagnosing major depressive disorder I. A psychometric evaluation of the DSM-IV symptom criteria. J Nerv Ment Dis 2006;194:158-63. 
31. Casarett D, Karlawish J, Sankar P, Hirschman K, Asch DA. Designing pain research from the patient's perspective: What trial end points are important to patients with chronic pain? Pain Med 2001;2:309-16.

32. Speilman AJ. Assessment of insomnia. Clin Psychol Rev 1986;6:11-26.

33. Morin CM. Insomnia: Psychological Assessment and Management. New York: Guilford, 1993.

34. Bootzin RR, Epstein DR. Understanding and treating insomnia. Annu Rev Clin Psychol 2011;7:435-58.

35. Currie SR, Wilson KG, Pontefract AJ, deLaplante L. Cognitive behavior therapy for insomnia secondary to chronic pain. J Consult Clin Psychol 2000;68:407-16.

36. Edinger JD, Wohlgemuth WK, Krystal AD, Rice JR. Behavioral insomnia therapy for fibromyalgia patients: A randomized clinical trial. Arch Intern Med 2005;165:2527-35.

37. Jungquist CR, O'Brien C, Matteson-Rusby S, et al. The efficacy of cognitive behavioral therapy for insomnia in patients with chronic pain. Sleep Med 2010;11:302-9.

38. Pigeon WR, Moynihan J, Matteson-Rusby S, et al. Comparative effectiveness of CBT interventions for co-morbid chronic pain and insomnia: A pilot study. Behav Res Ther 2012;50:685-9.

39. Rybarczyk B, Stepanski E, Fogg L, Lopez M, Barry P, Davis A A placebo-controlled test of cognitive-behavioral therapy for comorbid insomnia in older adults. J Consult Clin Psychol 2005; 73:1164-74.

40. Tang NKY, Goodchild CE, Salkovskis PM. Hybrid cognitivebehavior therapy for individuals with insomnia and chronic pain: A pilot randomised controlled trial. Behav Res Ther 2012;50:814-21.

41. Vitiello MV, Rybarczyk B, von Korff M, Stepanski E. Cognitive behavioral therapy for insomnia improves sleep and decreases pain in older adults with co-morbid insomnia and osteoarthritis. J Clin Sleep Med 2009;5:355-62.

42. Nicassio PM, Ormseth SR, Kay M, et al. The contribution of pain and depression to self-reported sleep disturbance in patients with rheumatoid arthritis. Pain 2012;153:107-12.

43. Tang NKY, Goodchild CE, Hester J, Salkovskis PM. Pain-related insomnia versus primary insomnia: A comparison study of sleep pattern, psychological characteristics, and cognitive-behavioral processes. Clin J Pain 2012;28:428-36.

44. Tang NKY, Goodchild CE, Sanborn AN, Howard J, Salkovskis PM. Deciphering the link between pain and sleep in a heterogeneous chronic pain patient sample: A multilevel daily process study. Sleep 2012;35:675-87A.

45. Kowal J, Wilson KG, Geck C, Henderson PR, D’Eon JL. Changes in perceived pain severity during interdisciplinary treatment for chronic pain. Pain Res Manag 2011;16:451-6.

46. Kowal J, Wilson, KG, McWilliams LA, Péloquin K, Duong D. Self-perceived burden to others in chronic pain: Relevance, prevalence, and predictors. Pain 2012;153:1735-41.

47. Haythornthwaite JA, Hegel MT, Kerns RD. Development of a sleep diary for chronic pain patients. J Pain Sympt Manage 1991;6:65-72.

48. Spitzer RL, Williams JB, Kroenke K, et al. Utility of a new procedure for diagnosing mental disorders in primary care: The PRIME-MD 1000 study. JAMA 1994;272:1749-56.

49. Wilson KG, Graham ID, Viola RA, et al. Structured interview assessment of symptoms and concerns in palliative care. Can J Psychiatry 2004:49:350-8.

50. Wilson KG, Chochinov HM, Skirko MG, et al. Depression and anxiety disorders in palliative cancer care. J Pain Sympt Manage 2007;33:118-29.

51. Schramm E, Hohagen F, Grasshoff U, et al. Test-retest reliability and validity of a Structured Interview for Sleep Disorders according to DSM-III-R (SIS-D). Am J Psychiatry 1993;150:867-72.

52. Endicott J, Spitzer RL. A diagnostic interview: The Schedule for Affective Disorders and Schizophrenia. Arch Gen Psychiatry 1978;35:837-44.
53. Jensen MP, Turner JA, Romano JM, Fisher LD. Comparative reliability and validity of chronic pain intensity measures. Pain 1999;83:157-62.

54. International Association for the Study of Pain: Pain Database Questionnaire. Seattle, 1995.

55. Steedman SM, Middaugh SJ, Kee WG, Carson DS, Harden RN, Miller MC. Chronic pain medications: Equivalence levels and method of quantifying usage. Clin J Pain 1992;8:204-14.

56. Harden RN, Weinland SR, Remble TA, et al. Medication Quantification Scale version III: Medication classes and revised detriment weights by survey of American Pain Society physicians. J Pain 2005;6:364-71.

57. Beck AT, Steer RA, Brown GK. Beck Depression Inventory-II Manual, 2nd edn. San Antonio: The Psychological Corporation, Harcourt Brace, 1996.

58. Arnau RC, Meagher MW, Norris MP, Bramson R. Psychometric evaluation of the Beck Depression Inventory-II with primary care medical patients. Health Psychol 2001;20:112-9.

59. Buysse DJ, Reynolds CF III, Monk TH, Berman SR, Kupfer DJ. The Pittsburgh Sleep Quality Index: A new instrument for psychiatric practice and research. Psychiatry Res 1989;28:193-213.

60. Wilson KG, Watson ST, Currie SR. Daily diary and ambulatory activity monitoring of sleep in patients with insomnia associated with chronic musculoskeletal pain. Pain 1998;75:75-84.

61. Lacks P, Rotert M. Knowledge and practice of sleep hygiene techniques in insomniacs and good sleepers. Behav Res Ther 1986;24:365-8.

62. Espie CA, Inglis SJ, Harvey L, Tessier S. Insomniacs' attributions: Psychometric properties of the Dysfunctional Beliefs and Attitudes about Sleep Scale. J Psychosom Res 2000;48:141-8.

63. Morin CM, Vallières A, Ivers H. Dysfunctional Attitudes and Beliefs about Sleep (DBAS): Validation of a brief version (DBAS-16). Sleep 2007;30:1547-54.

64. Jensen MP, McFarland CA. Increasing the reliability and validity of pain intensity measurement in chronic pain patients. Pain 1991;44:263-9.

65. Watson D, Clark LA, Tellegen A. Development and validation of brief measures of positive and negative affect. The PANAS scales. J Pers Soc Psychol 1988;54:1063-70.

66. Watson D, Clark LA. Measurement and mismeasurement of mood: Recurrent and emerging issues. J Pers Assess 1997;68:267-96.

67. Nicassio PM, Mendlowitz DR, Fussell JJ, Petras L. The phenomenology of the pre-sleep state: The development of the Pre-Sleep Arousal Scale. Behav Res Ther 1985;23:263-71.

68. Dar R, Serlin RC, Omer H. Misuse of statistical tests in three decades of psychotherapy research. J Consult Clin Psychol 1994;62:75-82.

69. Benjamini Y, Hochberg Y. Controlling the false discovery rate: A practical and powerful approach to multiple testing. J R Statist Soc B 1995;57:289-300.

70. Lavigne GJ, Nashed A, Manzini C, Carra MC. Does sleep differ among patients with common musculoskeletal pain disorders? Curr Rheumatol Rep 2011;13:535-42.

71. Harman K, Pivik RT, D'Eon JL, Wilson KG, Swenson JR, Matsunaga L. Sleep in depressed and non-depressed chronic low back pain participants: EEG and behavioral findings. Sleep 2002;25:775-83.

72. Smith MT, Haythornthwaite JA. Cognitive-behavioral treatment for insomnia and pain. In: Lavigne G, Sessle BJ, Choinière M, Soja PJ, eds. Sleep and Pain. Seattle: IASP Press, 2007:439-57.

73. McClintock SM, Husain MM, Wisniewski SR, et al. Residual symptoms in depressed outpatients who respond by $50 \%$ but do not remit to antidepressant medication. J Clin Psychopharmacol 2011;31:180-6.

74. Carney CE, Harris AL, Friedman J, Segal ZV. Residual sleep beliefs and sleep disturbance following cognitive behavioral therapy for major depression. Depress Anxiety 2011;28:464-70. 


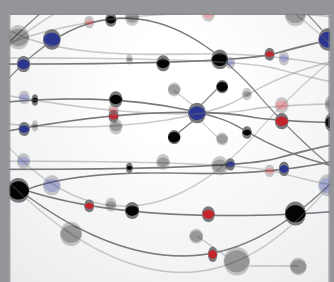

The Scientific World Journal
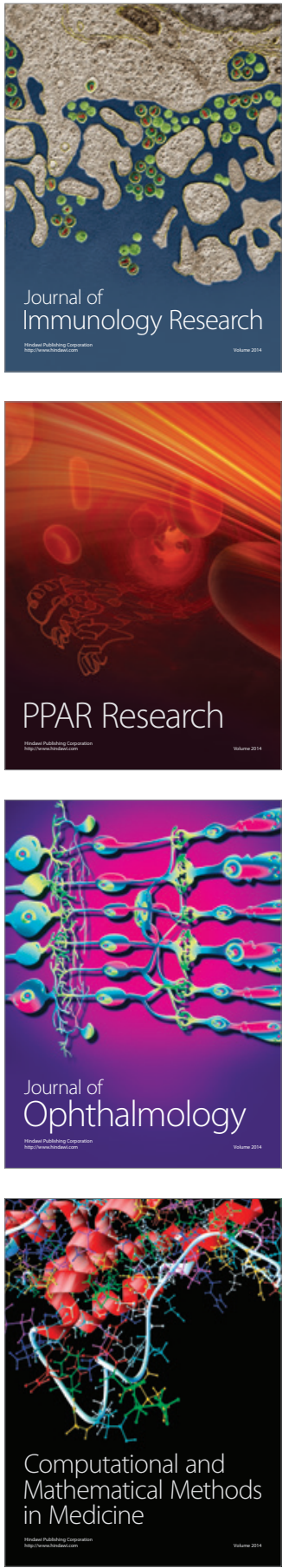

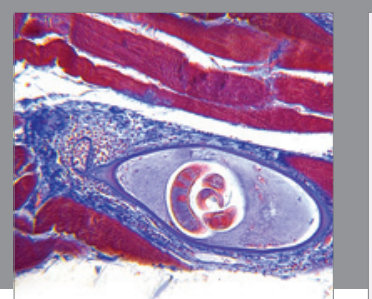

Gastroenterology Research and Practice

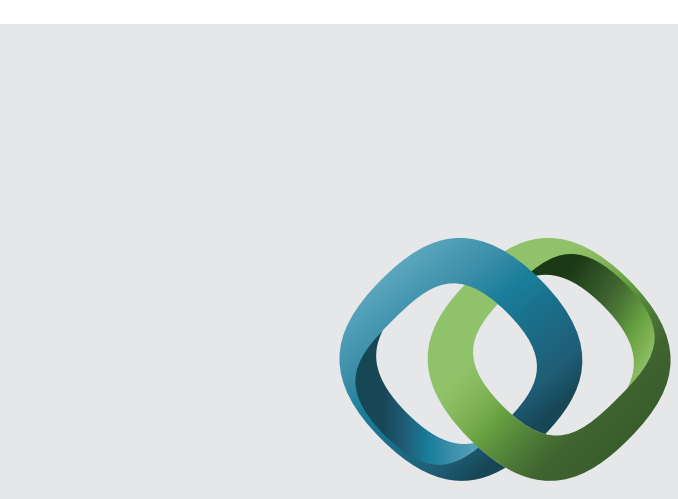

\section{Hindawi}

Submit your manuscripts at

http://www.hindawi.com
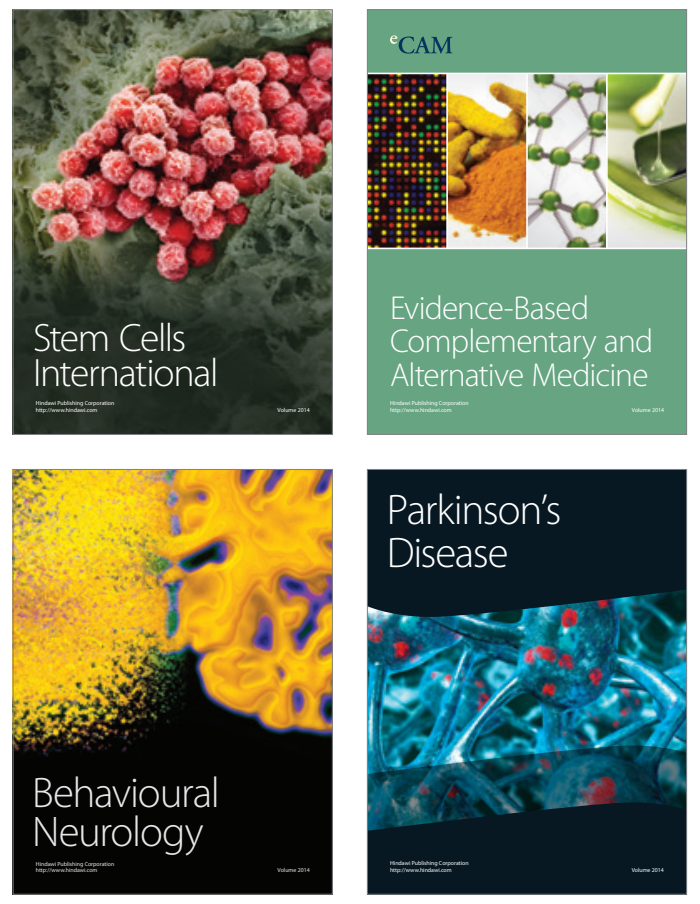
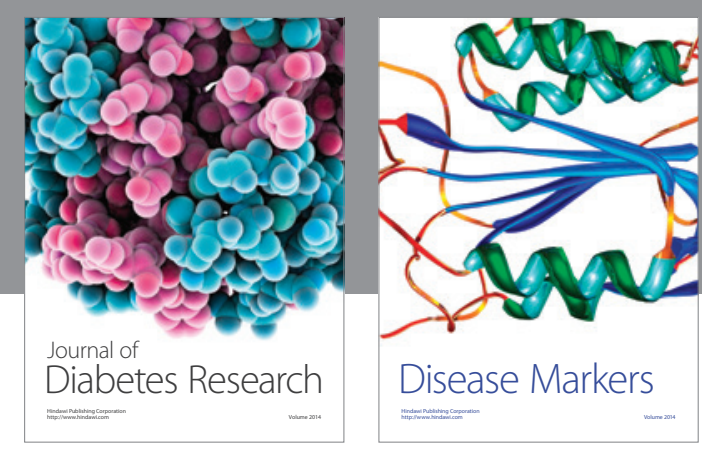

Disease Markers
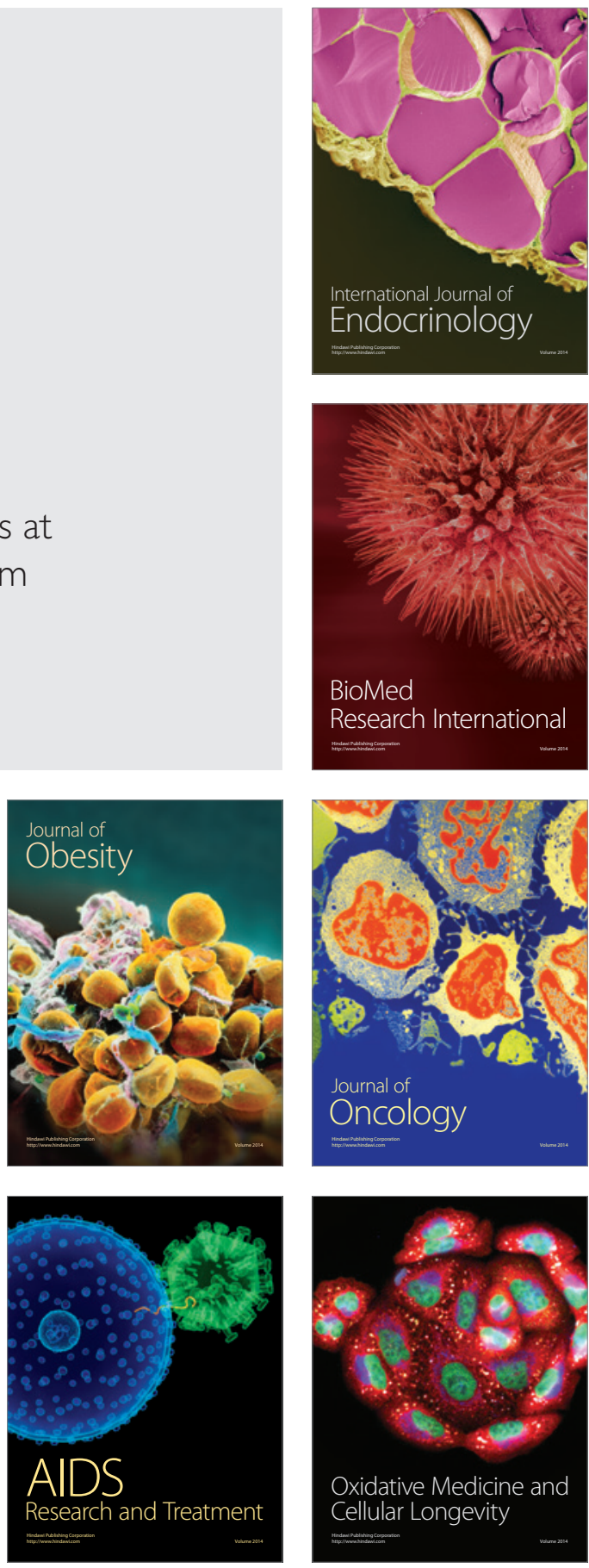